Basic Radio

By C. L. Boltz. (Nelson's Aeroscience Manuals.) Pp. 272. (Edinburgh and London: Thomas Nelson and Sons, Ltd., 1943.) 58. net.

7 HIS book is one of a series of manuals covering a range of subjects suited to the needs of aeronautical students. It is of the nature of an elementary text-book, illustrated occasionally with descriptions of typical experiments, and provided at the end of each chapter with a series of exercises to test the progress of the reader's knowledge. The scope of the book is more than is indicated by the title, since no prior knowledge of electricity is assumed, and the first half of the manual describes the fundamental properties of electric currents, how these are produced, and the heating, magnetic and chemical effects that result from their use. The notion of electric charge is not utilized until Chapter 6, on condensers, is reached ; and following this the nature of alternating currents is described and the manner in which these currents are affected by circuits containing inductance and capacitance. A chapter on waves describes the production of electromagnetic radiation from circuits carrying alternating currents of radio-frequency, and the main phenomena accompanying the transmission of wireless waves are dealt with very briefly. Five chapters in the later portion of the book describe the main facts concerning thermionic valves and the manner in which these are used for the generation of oscillations and for detection and amplification in wireless receivers. Other chapters deal with the use of aerials and feeders, and the methods of modulating the waves for signalling purposes.

Only the most elementary knowledge of mathematics and physics is assumed, and this can, if desired, be obtained from a perusal of other manuals in the same series. Although the subject-matter is arranged in such a way as to make this volume suitable for use as a class text-book, it will be found to be quite readable by the private student.

\section{Clouds and Weather Phenomena}

By C. J. P. Cave. Second edition, revised. Pp. viii $+24+42$ plates. (Cambridge: At the University Press, 1943.) 5s. net.

THIS little book contains a series of forty-two pictures of clouds, all beautiful examples of the photographer's art, and excellently reproduced, covering the common types of cloud. The letterpress of twenty-two pages begins with an account of the classification of clouds, including a brief but clear description of each type of cloud. There follows a discussion of the colour of the sky, sunset rays, the green ray, rainbows, haloes, coronæ, iridescent clouds, brocken spectres and mirages. The book contains a considerable amount of information of a character which is seldom to be found in books which aim at popularizing the study of meteorology, or even in more pretentious books

The author has aimed at providing for those who depict or watch the sky, a simple account of the colours and other phenomena which they see in the sky. He has achieved his aim in a marked degree, and has packed into the few pages of ietterpress much information which cannot fail to appeal to anyone who is interested in watching the sky. The book contains nothing too technical for any intelligent reader, and is one of the most satisfying books which have appeared in the field of meteorology for many years.

D. BRUNT.
Post-Graduate Lectures

Inorganic Chemistry, by Prof. H. J. Emeleus ; and Organic Chemistry, by Dr. H. B. Watson. Pp. 84. (London : Oil and Colour Chemists' Association, 1943.) $10 s$.

7 HIS slender volume contains lectures on some 1 interesting aspects of inorganic and organic chemistry which should be useful to those who have not kept abreast of modern work and wish to know something of its teachings. The topics are well chosen and are expounded in a clear and authoritative manner. Prof. Emeleus deals with the structure of inorganic compounds as determined by various methods, such as X-rays and electron diffraction, with crystals, silicates, radioactivity, the separation and applications of isotopes, reactions in gases and in non-aqueous solvents, and cognate subjects. The subject-matter is illustrated by clear and instructive diagrams, and many tables of useful numerical data are given.

Dr. Watson is concerned with showing how modern views on the electronic structure of atoms and mole. cules throw light on large groups of organic reactions; substitution, addition and isomeric change being chosen as typical. He gives references to original papers for those desiring more information. It is shown how many facts long known to organic chemists find a very lucid explanation when interpreted in the light of one or two quite simple assumptions, and thus organic chemistry is linked with general progress in theoretical physics.

Both sets of lectures are interesting, and a good deal of ground is covered in a way which should attract any reader wishing to learn something of the subjects with which they deal.

\section{Testing Radio Sets}

By J. H. Reyner. Fourth and revised edition. Pp. viii $+215+10$ plates. (London: Chapman and Hall, Ltd., 1943.) 15s. net

7 HOSE who have to use radio receiving sets, whether for the reception of broadcasting or communication signals, or as an auxiliary piece of equipment in various forms of radio-frequency measurements, are likely to require for occasional reference a book dealing with radio-receiver testing and fault-finding. The present book covers the technique of this subject in a clear and simple manner, and will be found to be a useful elementary manual for the constructor as well as to the serviceman and laboratory worker. The book was first published in 1930 , and the present fourth edition has received considerable revision and rearrangement in order to make it as up to date as possible under existing conditions.

\section{Electricity and Radio Transmission}

By Sir John Townsend. Pp. xi+183. (Winchester : Warren and Son, Ltd., 1943.) 8s. 6d. net.

7 HIS volume comprises an elementary and lucid 1 account of the main facts of electrostatics, magnetism and current electricity, leading thence by way of electromagnetic induction to oscillatory circuits and valve amplifiers and oscillators. An understanding of all this basic knowledge is necessary to a student who is taking an interest in the science of radio-communication, although much the same ground is covered by other elementary text-books. The author's object in presenting this book is, however, to demonstrate in a non-mathematical manner the relation of the principles of radio technique to other electrical phenomena. 